\title{
Revealing Dynamic Effects Of China's Regional Coal Consumption Control Policy On Energy Efficiency And Pollution Emissions
}

Zhao Wenjuan ( $\nabla_{\text {zhaowenjuan1012@163.com ) }}$

Tsinghua University

Huangfu Jianhua

Capital University of Economics and Business

Yu Lei

China Petroleum Planning \& Engineering Institute

\section{Research Article}

Keywords: Coal control policy, Emissions intensity, Energy intensity, SEM method

Posted Date: February 11th, 2022

DOI: https://doi.org/10.21203/rs.3.rs-1288951/v1

License: (c) (i) This work is licensed under a Creative Commons Attribution 4.0 International License. Read Full License 


\section{Abstract}

Up to now, far too little attention has been paid to comprehensively assessing the impact of the coal consumption constraint policy (CCCP) on energy intensity and pollution emissions based on China cities level. The present study explores the impact of CCCP on energy intensity and pollution emissions in a panel of 73 Chinese cities using an SEM approach from 2005 to 2019 . We find that the CCCP has significantly reduced $\mathrm{SO}_{2}$

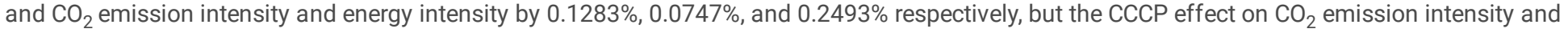
energy intensity has a lag of 3 years. Thus CCCP can effectively reduce emission intensity through industrial restructuring and technology advanced is the only effective way to reduce energy intensity. The study provides some valuable suggestions to enable the control of coal consumption.

\section{Introduction}

As the largest producer and consumer of coal globally, the coal-based energy structure has supported China's rapid economic development (Guo et al., 2020; Li et al., 2019). However, since 2011, China has consumed more coal than the rest of the world combined, and it emits about a quarter of the world's greenhouse gases, the largest share of any country (O'Meara, 2020), which limits the development of China's ecological environment (Jiang et al., 2018). In the face of economic growth and air quality challenges, China takes coal control as a core target of sustainable economic development and has adopted a series of policies and measures in recent years. In 2011, China introduced the "Energy Conservation and Emission Reduction Work Plan during the 12th FYP", which proposes to put into practice the coal consumption constraint policy (CCCP) in the pilot city. In 2016, China launched the additional coal capacity reduction policy "Notice on Coal Consumption Reduction and Substitution", expanding the pilot city to optimize the energy structure further and strengthen the implementation of the target to control total coal consumption. As a series of coal consumption constraint policies had been carried out for nearly a decade, there is an urgent need to quantitatively assess the impact of the policy to determine whether it has increased energy efficiency and reduced emissions.

As a typical command-and-control policy, the CCCP has fueled debates about its impact. It is widely accepted that coal control strategies are essential for improving air quality (Yang \& Teng, 2018). However, CCCP affects air pollution, $\mathrm{CO}_{2}$ emissions, economy, and energy intensity is still debatable. Some scholars predicted that CCCP will inevitably lead to a reduction in social welfare (Zhang et al., 2021) and economic development (Xiao et al., 2020) but could contribute to controlling environmental pollution emissions, such as SO2 and NOx, PM2.5, CO2 (Xiao et al., 2020). Conversely, there are also some researchers who believe that CCCP, a non-market driven policy, was technically infeasible (Shi et al., 2018), it not only allows for a significant increase in economic costs (Shi et al., 2018) but also led to a rise in pollution emissions and energy intensity (Guo et al., 2020), due to technical and cost barriers. As for the effect of CCCP on energy intensity, Shi et al. (2018) found that coal-to-gas policies have an insignificant negative effect on energy intensity in the Jing-Jin-Ji region. Guo et al. (2020) point out that CCCP fails to reduce the energy intensity based on 289 cities in China.

In terms of the archival path of ССCP impact, extensive research has shown because of the substitution effect from coal to natural gas and electricity (Shou et al., 2020), CCCP can reduce SO2, NOx, and $\mathrm{CO}_{2}$ emissions, and optimize energy structure (Chen \& Chen, 2019; Lin \& Jia, 2020). But Guo et al. (2021) argued that CCCP, as command-and-control environmental regulations, mainly reduced $\mathrm{CO}_{2}$ emissions by improving technology levels. To the best of our knowledge, there is no study that investigates the specific archival mechanism of CCCP effect at city levels. A few relevant studies focusing on cities only cover several large cities (Chen and Chen, 2017; Meng et al., 2017), due to the scarce of city-level data that cannot be generalized to most Chinese cities. Although Guo et al. (2020) conducted multi-city studies using data from the existing China City Statistical yearbook, they ignored the effects of CCCP on the second set of pilot projects introduced in 2016. Moreover, Guo et al. (2020) used the total energy consumption of 289 cities in China, but the data obtained were estimated based on provincial data which were not rigorous, and they did not provide a specific estimation method.

In this study, we provide the evaluation of the impact of CCCP on $\mathrm{CO} 2$ emissions, air pollution, and energy intensity based on realistic data from policy consecutive prospects. Furthermore, we employ an SEM model to track the specific realization path of CCCP affecting CO2 emissions, air pollution, and energy intensity. The main contributions of this paper are as follows. As an Economy-Energy-Environment (3E) database is constructed for analysis. As far as city-level database limited is concerned, there is little literature on total energy consumption at the city level. To fill the data gap, we constructed an Economy-Energy-Environment database including economic, environmental, total energy consumption indicators, and consumption indicators by energy species from 2005-2019 based on the original data from urban statistical yearbooks. Due to the lack of data for some cities, 73 cities with complete data were counted for empirical analysis in this paper.

As far as policy relevance and city limited is concerned, this study uses timing-varying DID to examine the synergistic effects of two consecutive typical CCCP policies on $\mathrm{CO}_{2}$ emissions, air pollution, and energy intensity based on 73 cities across the country. In contrast, most of the existing studies focus only on a single CCCP policy or in limited big cities using a Scenario method, which is insufficient and unrealistic, Comprehensive analysis based on realistic data reveals a broader and accurate picture of the effects of CCCP. Unlike previous studies that mainly explored the environmental and economic impacts of CCCP separately, this paper estimates the effects of CCCP from the intensity perspective, including greenhouse gas intensity, pollution emission intensity, and energy intensity, which helps us to effectively embody the efficiency of the policy implementation. For the very first time, a moderate model is introduced to more precisely identify the channels affecting greenhouse gas intensity, 
pollution emission intensity, and energy intensity. This analysis confirms the specific mechanism driving China's coal consumption. This helps policymakers to further formulate coal policies to balance the reduction of coal consumption with other desirable environmental effects.

${ }^{1}$ The Twelfth Five-year Plan for Energy Conservation and Emission Reduction (2011) set the first batch of CCCP pilot areas: the Jing-Jin-Ji Region (Beijing, Tianjin and Hebei province); the Long Triangle Area (Shanghai; Nanjing, Wuxi, Xuzhou, Changzhou, Suzhou, Nantong, Lianyungang, Huaian, Yancheng, Yangzhou, Zhenjiang, Taizhou, Suqian; Hangzhou, Ningbo, Wenzhou, Shaoxing, Jiaxing, Huzhou, Jinhua Quzhou, Zhoushan, Taizhou, Lishui), the Pearl River Delta Area (Guangzhou, Shenzhen, Zhuhai, Foshan, Jiangmen, Zhaoqing, Huizhou, Dongguan and Zhongshan) and Shandong province. In 2016, the Notice on Coal Consumption Reduction and Substitution added another batch: Liaoning Province and Henan Province.

\section{Literature Review}

There are a large number of published studies describing the effects of CCCP policies. From an economic perspective, the consequences of CCCP are unfavorable. Shi et al. (2018) pointed out that full compliance with CCCP would lead to a significant gap between supply and demand, resulting in a substantial increase in coal prices and economic costs. The effects of different policy instruments of the CCCP are significantly different on the macroeconomic system, but regardless of which policy tool is used, the CCCP will inevitably lead to a reduction in social welfare(Zhang et al., 2021). In contrast, (Li and Yao, 2020) demonstrated that CCCP contributed to energy conservation and carbon emission reduction, but only with a slight loss of economic efficiency. Chen and Chen (2019) focused on "2+26 cities" and predicted the environmental effect of CCCP in the building sector. The results showed that the policy could cause an increase in natural gas and electricity consumption, which could help reduce $\mathrm{SO}_{2}$ and $\mathrm{NO}_{\mathrm{x}}$ emissions, and it is helpful for some less developed areas to achieve the goal of low carbon faster. Ji et al. (2018) used Jiangsu province as a case study for the effect of CCCP. They found that a stricter target for CCCP would promote energy structure adjustment, curb pollution, and protect traditional energy resources. Compared with the analysis of the CCCP effect from an aggregate perspective, emission intensity and energy intensity in China have more research value because they are binding indicators for local government evaluation. However, there is a relatively small body of literature that focuses on energy intensity. Shi et al. (2018) take the Jing-Jin-Ji region as Study Subject and pointed out that coal-to-power and coalto-gas policies have an insignificant negative effect on energy intensity. Guo et al. (2020) expanded the scope of the study to 272 cities across the country, but they found that the CCCP introduced in 2011 had unexpectedly increased China's energy intensity, and only with the help of supportive policies, it can have a negative effect on energy intensity.

Air-pollutant emissions are relevant to economic development, industrial structure (Wang et al., 2019), technological innovation (Wang et al., 2019), population (Brajer et al., 2011), foreign direct investment (Copeland and Taylor, 1994; Jiang et al., 2014; Taylor and Copeland, 1997), energy structure (Xia et al., 2021). Greenhouse gas emissions are related to economic growth (Kivyiro and Arminen, 2014; Omri et al., 2014), foreign direct investment(Omri et al., 2014; Ren et al., 2014), energy structure (Akalpler and Shingil, 2017), industrial structure (Tian et al., 2014; Zhang and Deng, 2010), population (Dietz and Rosa, 1997), technological innovation (Chen and Lee, 2020), industrial structure (Wang et al., 2014).

A constant decline in energy intensity shows that a country's economic activities are moving toward a more ecological and sustainable mode(Ma and Yu, 2017). While a number of studies have examined the determinations of energy intensity and accepted that R\&D (Huang and Chen, 2020; Lin and Wang, 2014; Tan and Lin, 2018; Zheng et al., 2011), and GDP per capita (Wang and Han, 2017) are the most crucial factor in improving energy intensity. With the progress of economic globalization, research has shown that technology spillovers from foreign direct investment also affect energy intensity. However, it is controversial whether FDI contributes to reducing energy intensity (Bu et al., 2019; Mielnik and Goldemberg, 2002). Wu and Ding (2021) found that secondary industries consume more energy than other industries, as industrialization continues, energy intensity also increases (Chen \& Lee, 2020). Moreover, the impact of population on energy intensity is ambiguous: as an energy consumer, a large population would increase total energy consumption (Fu et al., 2015), but as a labour force, it would significantly increase GDP.

China's emissions mainly come from energy consumption in the production process. Three main emission reduction measures are typically taken by enterprises (Zhou et al., 2019), such as industrial restructuring, technological innovation, and optimizing the energy structure. Under the constraint of the CCCP, the industry is likely to prioritize dismantling backward capacity and replacing backward industries with high energy consumption and high environmental impact. Regarding technological innovation, to achieve stable and low energy consumption and sustainable development, enterprises increase research funds by strengthening internal technology (Ullah et al. 2021). On the other hand, they will also upgrade technology by introducing external resources, such as importing advanced energy-saving and environmental protection technologies, to achieve qualitative changes in energy use efficiency and reduce emission intensity. The energy substitution effect of switching the energy structure from coal-based to diversified energy sources also affects energy and emission intensity. Thus previous standard literature noted that CCCP reduced the energy intensity of emissions via industrial restructuring, technological innovation, optimizing the energy structure.

\section{Model And Method}

Following Zhang et al. (2018) and literature, we assume the coal consumption control policy is a key determinant of energy efficiency and pollution emissions. Thus, we begin with the following energy efficiency and pollution emissions models:

Page 3/12 
$\ln \left(\right.$ gso $\left._{i t}\right)=\beta_{0}+\beta_{1} D i t+\theta_{1} \ln \left(\right.$ pgdp $_{i t}+\theta_{2}$ industry $_{i t}+\theta_{4} \ln (\text { pop })_{i t}+\theta_{5} \ln (\operatorname{tec})_{i t}+\theta_{6} \ln (f d i)_{i t}+\theta_{7}$ coal_c $c+\mu_{i}+\gamma_{t}+\epsilon_{i t}$

1

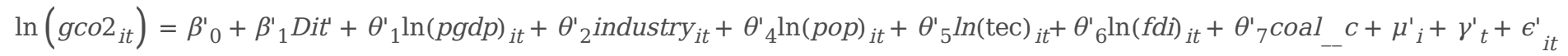

2

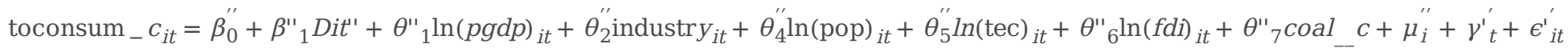

3

$D_{\text {it }}=$ treated $_{i}^{*}$ period $_{t}$

Where i and t denote cities and years, respectively; gso2 is a measure of so2 emission intensity; gco2 represents co2 emission intensity; and toconsum_c denotes energy intensity that depends on pgdp (GDP per capita), industry (secondary industry output value), FDI (foreign direct investment), coal_c (coal consumption in total energy consumption), pop (population), and tec (technological progress). The variable of interest is $\mathrm{D}_{i t} \mathrm{D}_{i t}{ }^{\prime}, \mathrm{D}_{i t}{ }^{\prime \prime}$, dummies that take the value of 1 in the years after city $\mathrm{i}$ implementing CCCP and 0 otherwise. The coefficients $\beta_{1}, \beta^{\prime}{ }_{1}, \beta^{\prime}{ }_{1}$, are the parameters to be estimated, representing the net effect of CCCP. A positive and significant one indicates the CCCP exerts a positive effect on the intensity of $\mathrm{SO}_{2}$ emission and $\mathrm{CO}_{2}$ emission, energy intensity, while a negative and significant one suggests that CCCP pushed intensity of $\mathrm{SO}_{2}$ emission and $\mathrm{CO}_{2}$ emission lower. While, $\mu_{\mathrm{i}}, \mu_{\mathrm{i}}^{\prime}, \mu^{\prime \prime}{ }_{\mathrm{i}}$ and $\gamma_{\mathrm{t}}, \gamma_{\mathrm{t}}^{\prime}, \gamma^{\prime}{ }_{\mathrm{t}}$ are vectors of city and year dummy variables that account for city and year fixed effects, but $\epsilon_{\text {it }}, \epsilon^{\prime}{ }_{\text {it }}, \epsilon^{\prime \prime}{ }_{\text {it }}$ are the random disturbance terms.

To further understand the specific implementation path of the policy, we employ the intermediate model to test which path-among adjusting the industrial structure, promoting technological progress, and reducing energy intensity-is most effective in reducing $\mathrm{CO}_{2}$ and $\mathrm{SO}_{2}$ emissions and energy intensity. The traditional multiple mediation model, a regression analysis based on the causality test proposed by Baron and Kenny (1986), is less efficient in estimating mediation effects(Fritz and MacKinnon, 2007). The Sobel test used in regression analysis assumes that a*b obeys a normal distribution, whereas mediation effects often do not meet the required, resulting in test results being relatively unreliable(Bollen and Stine, 1990; Stone and Sobel, 1990). SEM can address the shortcomings of the above methods. It is the best framework for mediated effects analysis because it can estimate all model parameters simultaneously and efficiently (Zhao et al., 2010). Therefore, this study explores the specific pathways through which CCCP works by building SEM models.

\section{Data}

This study examines the impact of CCCP on $\mathrm{CO} 2$ emissions, air pollution, and energy intensity by covering 73 cities of China over the period from 2005 to 2019. Table A1 reported the list of cities in the appendix. Therefore, $\mathrm{CO}_{2}$ emission, energy structure, and energy intensity coal consumption data were obtained based on our unique database. Specifically, we collected all data on 24 energy types published in the urban statistical yearbooks. Then, cities with missing for consecutive years were removed and the number of cities was finally set to 73 . The raw energy data are uniformly converted to standard coal and summed up so that we get the total energy consumption. Additionally, as for coal consumption, it is calculated using 12 coal energies of the industry which is uniformly converted to standard coal and summed up. The rest of the data come from the China city statistical yearbooks. The variables description and descriptive statistics of the variables are shown in Table 1. 
Table 1

Variable description

\begin{tabular}{|c|c|c|c|c|}
\hline Symbol & Variable & Unit & Mean & S.D \\
\hline $\mathrm{gsO}_{2}$ & $\begin{array}{l}\text { Sulphur dioxide emissions from industrial sector per unit of output } \\
\text { value }\end{array}$ & Tones /CNY & 0.00429 & 0.00664 \\
\hline $\mathrm{gcO}_{2}$ & $\begin{array}{l}\text { Carbon dioxide emissions from industrial sector per unit of output } \\
\text { value }\end{array}$ & Tones /CNY & 0.00047 & 0.00068 \\
\hline toconsum_g & Ratio of Energy consumption to output value & N/A & 1.12860 & 1.55894 \\
\hline pgdp & GDP per capita & CNY/people & 73465.8 & 66010.7 \\
\hline industry & The proportion of secondary industry in total output value & $\%$ & 47.9730 & 9.36703 \\
\hline pop & Total population at the end of the year & Million & 440.943 & 440.943 \\
\hline tec & the proportion of Scientific expenditure in Local fiscal expenditure & N/A & 0.02265 & 0.01823 \\
\hline fdi & $\begin{array}{l}\text { the proportion of Actual amount of foreign capital used in the year of } \\
\text { GDP }\end{array}$ & $\begin{array}{l}\text { million USD/ ten thousand } \\
\text { CNY }\end{array}$ & 0.00427 & 0.00347 \\
\hline Coal_c & the proportion of coal consumption in total energy consumption & N/A & 0.66348 & 0.24356 \\
\hline
\end{tabular}

${ }^{2}$ Raw Coal, Finely washed coal, Other washed coal, Briquette, Other coal products (pulverized coal, coal water slurry), Coke, Crude Oil, Fuel oil, Gasoline, Diesel oil, General kerosene, Refinery thousand gas, Liquefied Natural Gas, Liquefied Petroleum Gas, Naphtha, Other petroleum products, Natural Gas, Blast Furnace Gas, Converter Gas, Coke Oven Gas, Other Gas, Heat, Electricity.

${ }^{3}$ Raw coal, washed coal, other washed coal, coal products, coke, other coking products, coke oven gas, blast furnace gas, converter gas, producer gas, other coal gas

${ }^{4}$ Available website of China City Statistical yearbook: http://data.cnki.net

\section{Results And Discussion}

In Table 2, findings of time-varying DID show that CCCP can significantly reduce the intensity of CO2 and SO2 emissions as well as energy intensity. The finding indicates that CCCP has decreased so 2 intensity by $0.1283 \%$ and co 2 emission intensity $0.0747 \%$. Such results demonstrate that the CCCP, developed with air pollution control as the starting point, can achieve synergistic control of greenhouse gases and air pollutants. There are two possible explanations are that fossil fuel combustion is a significant cause of air pollution and an important anthropogenic source of greenhouse gases. Conventional air pollutants such as SO2 have a high degree of structural similarity to $\mathrm{CO} 2$ emissions. Therefore, limiting coal consumption, which is the primary energy source in China, can simultaneously reduce $\mathrm{CO} 2$ and air pollutants emissions, leading to co-control effects for the climate and the environment. Findings infer that two different types of environmental problems, air pollution, and greenhouse gases, are mostly driven by the same energy production and consumption patterns and therefore have the same emission reduction pathways. The effect of the coal reduction policy on energy intensity is negative significant and indicates that the implementation of the CCCP significantly reduces energy intensity by $-0.249 \%$. This means that technological progress and economic development are the most critical factors in reducing energy intensity. 
Table 2

Estimation results of $\mathrm{CCCP}$, energy efficiency, and pollution emissions

\begin{tabular}{|c|c|c|c|}
\hline & Ingso2 & Ing_co2 & toconsum_g \\
\hline & Eq. (1) & Eq. (2) & Eq. (3) \\
\hline \multirow[t]{2}{*}{$\mathrm{D}$} & $-0.1283^{\star *}$ & $-0.0747^{*}$ & $-0.2493^{\star *}$ \\
\hline & $(-2.2283)$ & $(-1.7183)$ & $(-2.0735)$ \\
\hline \multirow[t]{2}{*}{ Inpgdp } & $-0.6909^{\star \star \star}$ & $-0.8116^{\star \star \star}$ & $-0.4622^{*}$ \\
\hline & $(-4.3276)$ & $(-6.7058)$ & $(-1.8887)$ \\
\hline \multirow[t]{2}{*}{ industry } & $0.0122^{\star \star}$ & $0.0119^{\star \star \star}$ & -0.0196 \\
\hline & -2.2196 & -2.8816 & $(-1.5973)$ \\
\hline \multirow[t]{2}{*}{ Inpop } & $-1.6557^{\star \star \star}$ & $-0.8276^{\star \star}$ & 0.7567 \\
\hline & $(-3.8338)$ & $(-2.0245)$ & -1.4118 \\
\hline \multirow[t]{2}{*}{ Intec } & -0.0104 & -0.0466 & $-0.2061^{\star \star}$ \\
\hline & $(-0.2037)$ & $(-1.1212)$ & $(-2.4355)$ \\
\hline \multirow[t]{2}{*}{ Infdi } & $-0.0853^{\star \star \star}$ & -0.0076 & -0.0708 \\
\hline & $(-3.1015)$ & $(-0.4092)$ & $(-1.5524)$ \\
\hline \multirow[t]{2}{*}{ coal_c } & -0.2412 & $0.4925^{\star}$ & 0.4498 \\
\hline & $(-1.5949)$ & -1.8374 & -1.0179 \\
\hline \multirow[t]{2}{*}{ _cons } & $10.5287^{\star \star \star}$ & 4.4165 & 0.9128 \\
\hline & $(2.8337)$ & $(2.8337)$ & $(2.8337)$ \\
\hline city & yes & yes & yes \\
\hline year & yes & yes & yes \\
\hline$N$ & 992 & 1026 & 1030 \\
\hline r2_a & 0.9266 & 0.9203 & 0.7402 \\
\hline
\end{tabular}

Table 3 reported the results of robustness. We assume that the CCCP was implemented 2 or 3 years ahead of schedule. Specifically, it is supposed that the first CCCP proposal was implemented in 2008 and 2009 and that the pilot cities were expanded in 2013 and 2014 , respectively. Therefore, variables D_2 and D_3 are constructed as virtual policy dummies to reexamine counterfactual event effects. From Table 3, it can be seen that the coefficients of the effects of virtual policy (D_2/D_3) are not significant for both virtual policy times, and this result supports the hypothesis of the randomness of the timing of policy implementation. Therefore, the previously obtained results are robust and reliable. 
Table 3

Estimation results of CCCP, energy efficiency, and pollution emissions (robustness)

\begin{tabular}{|c|c|c|c|c|c|c|}
\hline & Ingso2 & Ing_co2 & toconsum_g & Ingso2 & Ing_co2 & toconsum_g \\
\hline & (1) & (2) & (3) & (4) & (5) & (6) \\
\hline \multirow[t]{2}{*}{ D_2 } & -0.0941 & -0.0701 & -0.0416 & & & \\
\hline & $(-1.6029)$ & $(-1.5137)$ & $(-0.3607)$ & & & \\
\hline \multirow[t]{2}{*}{ D_3 } & & & & -0.0844 & -0.0479 & 0.0380 \\
\hline & & & & $(-1.3439)$ & $(-0.9361)$ & $(0.3229)$ \\
\hline \multirow[t]{2}{*}{ Inpgdp } & $-0.6673^{\star \star \star}$ & $-0.8094^{\star \star \star}$ & -0.3294 & $-0.6534^{\star \star \star}$ & $-0.7912^{\star \star \star}$ & -0.2804 \\
\hline & $(-4.1203)$ & $(-6.7011)$ & $(-1.3835)$ & $(-4.0681)$ & $(-6.5723)$ & $(-1.1499)$ \\
\hline \multirow[t]{2}{*}{ industry } & $0.0129^{\star \star}$ & $0.0121^{\star \star \star}$ & -0.0166 & $0.0131^{\star \star}$ & $0.0124^{\star \star \star}$ & -0.0158 \\
\hline & $(2.3602)$ & $(2.9812)$ & $(-1.3676)$ & $(2.4051)$ & $(3.0756)$ & $(-1.3208)$ \\
\hline \multirow[t]{2}{*}{ Inpop } & $-1.6677^{\star \star \star}$ & $-0.8401^{\star \star}$ & 0.7645 & $-1.6671^{\star \star \star}$ & $-0.8369^{\star \star}$ & 0.7870 \\
\hline & $(-3.8721)$ & $(-2.0501)$ & $(1.4305)$ & $(-3.8690)$ & $(-2.0450)$ & $(1.4698)$ \\
\hline \multirow[t]{2}{*}{ Intec } & -0.0139 & -0.0468 & $-0.2325^{\star \star \star}$ & -0.0163 & -0.0502 & $-0.2429^{\star \star \star}$ \\
\hline & $(-0.2682)$ & $(-1.1126)$ & $(-2.6855)$ & $(-0.3137)$ & $(-1.1978)$ & $(-2.7677)$ \\
\hline \multirow[t]{2}{*}{ Infdi } & $-0.0847^{\star \star \star}$ & -0.0081 & -0.0640 & $-0.0841^{\star \star \star}$ & -0.0071 & -0.0604 \\
\hline & $(-3.0787)$ & $(-0.4376)$ & $(-1.4122)$ & $(-3.0546)$ & $(-0.3796)$ & $(-1.3397)$ \\
\hline \multirow[t]{2}{*}{ coal_c } & -0.2413 & $0.4885^{*}$ & 0.4847 & -0.2293 & $0.4992^{*}$ & 0.5005 \\
\hline & $(-1.6269)$ & $(1.8240)$ & (1.0935) & $(-1.5492)$ & $(1.8623)$ & $(1.1235)$ \\
\hline \multirow[t]{2}{*}{ _cons } & $10.3020^{\star \star \star}$ & 4.4608 & -0.8777 & $10.1231^{\star \star \star}$ & 4.2057 & -1.6543 \\
\hline & $(2.7321)$ & $(1.4621)$ & $(-0.1667)$ & $(2.6912)$ & $(1.3874)$ & $(-0.3105)$ \\
\hline$N$ & 992 & 1026 & 1030 & 992 & 1026 & 1030 \\
\hline r2_a & 0.9263 & 0.9202 & 0.7386 & 0.9263 & 0.9201 & 0.7386 \\
\hline
\end{tabular}

The results of time-varying DID show that the CCCP can significantly reduce the carbon emission intensity, So2 emission intensity, and energy intensity of the pilot cities. To further investigate the specific realization path of CCCP implementation to reduce $\mathrm{CO} 2$ and SO2 emission intensity and energy intensity, throw light on the effective initiatives of China. The SEM model is employed in this paper; we select technological progress, energy intensity, and industrial structure as mediating variables for mediation analysis according to the analysis of the mechanism of CCCP. Furthermore, due to the nonlinear distributional properties of the mediation effects, a nonparametric bootstrapping method is used in this paper to adjust the estimation bias (MacKinnon et al. 2004).

The finding of Table 4 shows intermediary effects of co2 emission intensity. The confidence interval (BC and $\mathrm{p}$ interval $95 \%$ ) of the direct effect contains 0 , indicating that the direct effect of coal reduction policy on $\mathrm{CO} 2$ intensity is not significant and is a fully mediated effect. In addition, the coefficient of the mediated effect of CCCP $\rightarrow$ industrial structure $\rightarrow$ CO2 intensity is $-2.629 \%$, the confidence interval (BC interval $95 \%$ ) does not contain 0 , denoting that industrial restructuring is an important mechanism for CCCP to reduce co 2 intensity. In contrast, the confidence interval of the mediating effect of coal reduction policy $\rightarrow$ technological progress $\rightarrow \mathrm{CO} 2$ intensity and coal reduction policy $\rightarrow$ energy structure $\rightarrow$ CO2 intensity both contain 0 , representing that CCCP does not effectively reduce $\mathrm{CO} 2$ intensity by technological progress and energy structure optimization. 
Table 4

The indirect effects of $\mathrm{Co} 2$ emission intensity

\begin{tabular}{|c|c|c|c|c|c|c|}
\hline & & Bootstrap & & & & \\
\hline & Observed coefficient & Bias & std. err. & [95\% conf. in & erval] & \\
\hline \multirow[t]{2}{*}{ direct_effect } & -0.0746954 & 0.000663 & 0.04698125 & -0.1726226 & 0.0156783 & $(P)$ \\
\hline & & & & -0.1726226 & 0.0156783 & $(\mathrm{BC})$ \\
\hline \multirow[t]{2}{*}{ industry structure } & -0.0262948 & 0.0000226 & 0.01129858 & -0.0489928 & -0.0043092 & $(P)$ \\
\hline & & & & -0.0507158 & -0.005986 & $(\mathrm{BC})$ \\
\hline \multirow[t]{2}{*}{ Technological progress } & -0.012196 & 0.0013554 & 0.01122607 & -0.0330336 & 0.0129179 & $(P)$ \\
\hline & & & & -0.0356763 & 0.0089997 & $(\mathrm{BC})$ \\
\hline \multirow[t]{2}{*}{ energy structure } & -0.0191922 & -0.0001317 & 0.01347696 & -0.0518248 & 0.0025728 & $(P)$ \\
\hline & & & & -0.0547955 & 0.0006668 & $(\mathrm{BC})$ \\
\hline \multirow[t]{2}{*}{ total_effect) } & -0.1323784 & 0.0019093 & 0.04789469 & -0.2291923 & -0.0414706 & $(P)$ \\
\hline & & & & -0.2297478 & -0.0424466 & $(\mathrm{BC})$ \\
\hline
\end{tabular}

If the $95 \%$ confidence interval excludes zero, it means that the mediator is statistically significant at the $5 \%$ level, otherwise, it is not significant.

Table 5 shows the results of the intermediary effects of so 2 emission intensity. The direct effect coefficient is $-12.829342 \%$ and the confidence interval (BC/p interval 95\%) does not contain 0, indicating that the direct effect of CCCP on SO2 intensity is significant and partially mediated. Furthermore, the coefficient of the mediating effect of CCCP $\rightarrow$ industrial structure $\rightarrow \mathrm{CO} 2$ intensity is $-2.706938 \%$ and the confidence interval (BC interval and $P$ interval 95\%) is [-0.052486 -0.0037105] and [-0.0525165 -0.0040274] do not contain 0 . This means that CCCP can reduce so2 emission intensity by industry structure adjustment. whereas the confidence interval of the mediating effect of CCCP $\rightarrow$ technological progress $\rightarrow$ so2 emission intensity and CCCP $\rightarrow$ energy structure $\rightarrow$ so 2 emission intensity both contain 0 , demonstrating that CCCP does not effectively reduce so2 emission intensity by industrial structure adjustment and energy structure optimization.

Table 5

The indirect effects of so 2 emission intensity

\begin{tabular}{|c|c|c|c|c|c|c|}
\hline \multirow[b]{3}{*}{ direct_effect } & \multirow{3}{*}{$\begin{array}{l}\text { Observed coefficient } \\
-0.12829342\end{array}$} & \multicolumn{5}{|l|}{ Bootstrap } \\
\hline & & Bias & std. err. & \multicolumn{3}{|c|}{ [95\% conf. interval] } \\
\hline & & -0.0017824 & 0.05851224 & -0.234171 & -0.0134352 & $(P)$ \\
\hline & & & & -0.2302709 & -0.0059331 & $(\mathrm{BC})$ \\
\hline \multirow[t]{2}{*}{ industry structure } & -0.02706938 & -0.0005438 & 0.01303123 & -0.052486 & -0.0037105 & $(P)$ \\
\hline & & & & -0.0525165 & -0.0040274 & $(\mathrm{BC})$ \\
\hline \multirow[t]{2}{*}{ Technological progress } & -0.00272681 & 0.0009228 & 0.01374639 & -0.0295337 & 0.0241927 & $(P)$ \\
\hline & & & & -0.0312444 & 0.0226518 & $(\mathrm{BC})$ \\
\hline \multirow[t]{2}{*}{ energy structure } & 0.00940099 & 0.0000126 & 0.00751437 & -0.0008967 & 0.0268915 & $(P)$ \\
\hline & & & & -0.0001102 & 0.0317229 & $(\mathrm{BC})$ \\
\hline \multirow[t]{2}{*}{ total_effect) } & -0.14868861 & -0.0013908 & 0.05715134 & -0.2570741 & -0.0358164 & $(\mathrm{P})$ \\
\hline & & & & -0.252479 & -0.0299322 & $(\mathrm{BC})$ \\
\hline
\end{tabular}

Similarly, the estimation results of the indirect effects of energy intensity are presented in Table 6 . The confidence interval for the direct effect (BC interval $95 \%$ and $\mathrm{P}$ interval 95\%) contains 0 , indicating that the direct suppression effect of coal reduction policy on energy intensity is not significant and it is a fully mediated effect. Additionally, the coefficient of the mediated effect of CCCP $\rightarrow$ technological progress $\rightarrow$ energy intensity is $-5.389825 \%$, and the confidence interval (BC interval 95\%/ P interval 95\%) does not contain 0 . The CCCP was able to effectively reduce energy intensity through increased technological progress in industrial production, caused by the innovation compensation effect promoted by the command-and-control policy of the government. While the confidence interval of the mediating effect of coal production reduction policy $\rightarrow$ industry 
structure $\rightarrow$ energy intensity and coal production reduction policy $\rightarrow$ energy structure $\rightarrow$ energy intensity both contains 0 , indicating that coal production reduction policy is not effective in reducing energy intensity through the industry structure adjustment and energy structure optimization.

Table 6

The indirect effects of energy intensity

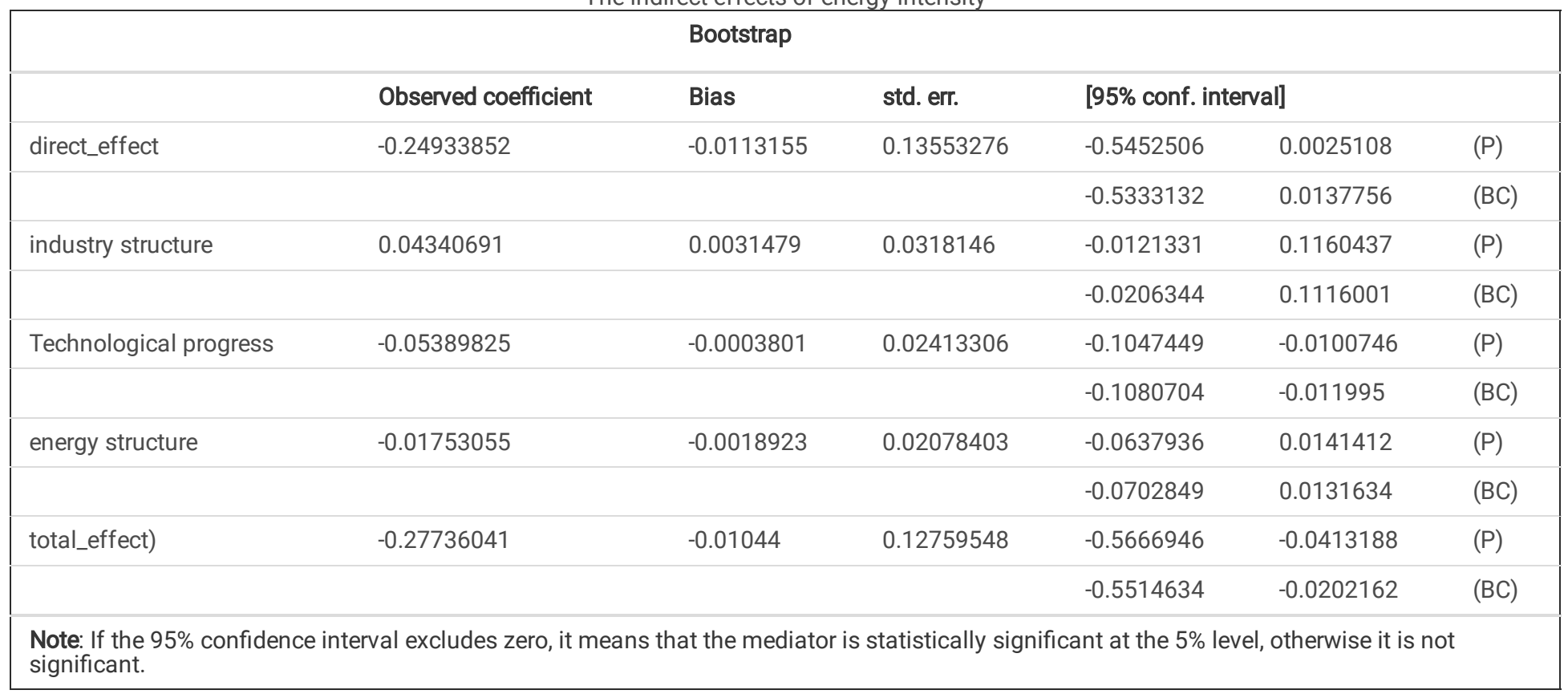

Our findings show that CСCP can effectively reduce emissions by restructuring the industry, rather than in other ways. To facilitate the implementation of the CСCP policy, China has set a strict ratio of backward production capacity elimination and forced the closure of more than 1,000 backward coal mines. As a command-and-control policy, by setting a strict backward industry goal for local governments and enterprises, the effect of CCCP is ensured effectively. What is surprising is that China invests tons of financial support to the enterprise to replace coal with other clean energy, but adjust energy structure fail to reduce emissions significantly. This may be due to the fact that the CCCP, as a command-andcontrol policy, encourages the reduction of coal quantity and the use of alternative energy sources, which likely leads to a loss of resource allocation efficiency (Shao et al., 2019). The loss of efficiency in coal resource allocation may lead to an increase in total energy consumption, which not significantly beneficial to emission intensity. Whereas advancing technology, which is a fundamental solution to achieve industrial transformation and upgrading and ultra-low emission and energy consumption (Anadon et al., 2011; Gallagher et al., 2006), does not act as a significant mediator. In contrast, energy intensity, to which China attaches greater importance, can only be reduced through technological advances. Mandatory measures, such as restructuring the industrial and energy structure, have not played a significant role in reducing energy intensity.

\section{Conclusions And Policy Implementations}

This study examines the impact of energy efficiency and pollution emissions from the perspective of continuity of policies implemented in 2011 and 2016 based on the SEM method, using special panel data of 73 Chinese cities from 2005 to 2019. Our SEM findings identified that CCCP has co-benefits of reducing emissions intensity and optimizing energy efficiency. As expected, it has led to a reduction in China's So2 emission intensity, CO2 emission intensity, and energy intensity by $0.1283 \%, 0.0747 \%, 0.2493 \%$ respectively in the pilot cities compared to other cities. The study also shows that CCCP, as a command-and-control policy, is effective to curb emissions intensity by industrial restructuring, rather than in progressing technology and optimizing the energy structure. Whereas, technology advanced is the only effective way to reduce energy intensity.

The above findings have significant policy implications. Firstly, greater efforts are needed to ensure the expected effectiveness and reduce the time required for policy action. The government should play a key role in coordinating the various issues involved and take steps to avoid policy fragmentation and reduce the cost of friction between the various institutions involved. Secondly, the optimization effect of industrial structure as a crucial mechanism to reduce emission intensity plays an important role in environmentally balanced development. Therefore, in adjusting the industrial structure with the support of government financing for environmental protection, attention should be paid to raising the entry threshold for enterprises with high energy consumption and promoting and developing green industries with high added value. Finally, the synergistic mechanism of environmental governance and structural optimization should be used to revitalize the city's innovation momentum, increase support for emission reduction R\&D technologies, and promote a green orientation of R\&D investment.

There are some limitations to our research: This study uses data from the industrial sector only by ignoring other sectors. The limited data may lead to an underestimation of the effect of CCCP on environmental pollution. Although we are shifting our eye contact from a few major cities in the 
north to 73 cities across the country, this cannot yet be applied to all Chinese cities. Therefore, we should consider a broader range of cities in our future research.

\section{Appendix}

Table A1: List of 73 cities

\section{CCCP pilot cities in 2011}

Tianjin, Beijing, Tangshan, Shijiazhuang, Handan, Jinan, Jining Weifang, Qingdao, Zhongshan, Foshan, Guangzhou, Huizhou, Jiangmen, Shenzhen, Zhangqing, Zhuhai, Shanghai, Nanjing, Nantong, Taizhou, Hefei, Jiaxing, Ningbo, Suqian, Changzhou, Wuxi, Wenzhou, Huzhou, Yancheng, Shaoxing, Suzhou, Lianyungang, Jinhua, Zhenjiang, Maanshan

\section{New added without CCCP cities pilot cities in 2016}

Nanyang, Baotou, Chengdu, Fuzhou, Guiyang, Guilin, Harbin, Dalian, Haikou, Hohhot, Jincheng, Jingzhou, Kunming, Shenyang, Nanchang, Nanning, Xiamen, Shangrao, Shuozhou, Zhengzhou Siping, Taiyuan, Urumqi, Xi'an, Xianning, Xianyang, Xinzhou, Xinyu, Yangquan, Yichang, Yinchuan, Yulin, Changchun, Changsha, Changzhi, Chongqing, Zunyi, the

\section{Declarations}

Ethical Approval: Not applicable

Consent to Participate: I am free to contact any of the people involved in the research to seek further clarification and information

Consent to Publish: Not applicable

Authors' Contributions: This idea was given by Zhao Wenjuan. Zhao Wenjuan and Huangfu Jianhua analyzed the data and wrote the complete paper. While Yu Lei read and approved the final version.

Funding: Not applicable

Competing Interests: The authors declare that they have no conflict of interest.

Availability of data and materials: The datasets used and/or analyzed during the current study are available from the corresponding author on reasonable request.

\section{References}

1. Akalpler E, Shingil ME (2017) Statistical reasoning the link between energy demand, CO2 emissions and growth: Evidence from China. Procedia Comput Sci 120:182-188. https://doi.org/10.1016/j.procs.2017.11.227

2. Anadon LD, Bunn M, Chan G, Chan M, Jones C, Kempener R (2011)Transforming U.S. Energy Innovation (Policy Brief)

3. Beck T, Levine R, Levkov A (2010) Big bad banks? The winners and losers from bank deregulation in the United States. J Finance 65:16371667. https://doi.org/10.1111/j.1540-6261.2010.01589.x

4. Bollen KA, Stine R (1990) Direct and Indirect Effects: Classical and Bootstrap Estimates of Variability. Sociol Methodol $20: 115$. https://doi.org/10.2307/271084

5. Brajer V, Mead RW, Xiao F (2011) Searching for an Environmental Kuznets Curve in China's air pollution. China Econ Rev 22:383-397. https://doi.org/10.1016/j.chieco.2011.05.001

6. Bu M, Li S, Jiang L (2019) Foreign direct investment and energy intensity in China: Firm-level evidence. Energy Econ 80:366-376. https://doi.org/10.1016/j.eneco.2019.01.003

7. Chen H, Chen W (2019) Potential impacts of coal substitution policy on regional air pollutants and carbon emission reductions for China's building sector during the 13th Five-Year Plan period. Energy Policy 131:281-294. https://doi.org/10.1016/j.enpol.2019.04.047

8. Chen S, Chen B (2017) Coupling of carbon and energy flows in cities: A meta-analysis and nexus modelling. Appl Energy 194:774-783. https://doi.org/10.1016/j.apenergy.2016.10.069

9. Chen Y, Lee CC (2020) Does technological innovation reduce CO2 emissions?Cross-country evidence. J Clean Prod 263:121550. https://doi.org/10.1016/j.jclepro.2020.121550

10. Copeland BR, Taylor MS (1994) North-South Trade and the Environment Author (s): Brian R. Copeland and M. Scott Taylor. Q. J. Econ. 109, 755-787

11. Dietz T, Rosa EA (1997) Effects of population and affluence on CO2 emissions. Proc. Natl. Acad. Sci. U. S. A. 94, $175-179$. https://doi.org/10.1073/pnas.94.1.175 
12. Fritz MS, MacKinnon DP (2007) Required sample size to detect the mediated effect. Psychol Sci 18:233-239. https://doi.org/10.1111/j.14679280.2007.01882.x

13. Gallagher KS, Holdren JP, Sagar AD (2006) Energy-technology innovation. Annu Rev Environ Resour 31:193-237. https://doi.org/10.1146/annurev.energy.30.050504.144321

14. Guo X, Fu L, Sun X (2021) Can environmental regulations promote greenhouse gas abatement in oecd countries? Command-and-control vs. market-based policies. Sustain 13. https://doi.org/10.3390/su13126913

15. Guo X, Xiao B, Song L (2020) Emission reduction and energy-intensity enhancement: The expected and unexpected consequences of China's coal consumption constraint policy. J Clean Prod 271:122691. https://doi.org/10.1016/j.jclepro.2020.122691

16. Han ZY, Fan Y, Jiao JL, Yan JS, Wei YM (2007) Energy structure, marginal efficiency and substitution rate: An empirical study of China. Energy 32:935-942. https://doi.org/10.1016/j.energy.2006.10.008

17. Huang J, Chen X (2020) Domestic R\&D activities, technology absorption ability, and energy intensity in China. Energy Policy $138: 111184$. https://doi.org/10.1016/j.enpol.2019.111184

18. Ji L, Zhang BB, Huang GH, Xie YL, Niu DX (2018) GHG-mitigation oriented and coal-consumption constrained inexact robust model for regional energy structure adjustment - A case study for Jiangsu Province, China. Renew Energy 123:549-562.

https://doi.org/10.1016/j.renene.2018.02.059

19. Jiang L, Folmer H, Ji M (2014) The drivers of energy intensity in China: A spatial panel data approach. China Econ Rev 31:351-360. https://doi.org/10.1016/j.chieco.2014.10.003

20. Jiang S, Yang C, Guo J, Ding Z (2018) Energy Sources Part B Econ Plan Policy 13:190-195. https://doi.org/10.1080/15567249.2017.1423413. ARIMA forecasting of China's coal consumption, price and investment by 2030

21. Jing Q, Bai H, Luo W, Cai B, Xu H (2018) A top-bottom method for city-scale energy-related CO2 emissions estimation: A case study of 41 Chinese cities. J Clean Prod 202:444-455. https://doi.org/10.1016/j.jclepro.2018.08.179

22. Kivyiro P, Arminen H (2014) Carbon dioxide emissions, energy consumption, economic growth, and foreign direct investment: Causality analysis for Sub-Saharan Africa. Energy 74:595-606. https://doi.org/10.1016/j.energy.2014.07.025

23. Li R, Leung GCK (2012) Coal consumption and economic growth in China. Energy Policy 40:438-443. https://doi.org/10.1016/j.enpol.2011.10.034

24. Li X, Yao X (2020) Can energy supply-side and demand-side policies for energy saving and emission reduction be synergistic?-A simulated study on China's coal capacity cut and carbon tax. Energy Policy 138:111232. https://doi.org/10.1016/j.enpol.2019.111232

25. Li Y, Chiu Y, ho, Lin TY (2019) Coal production efficiency and land destruction in China's coal mining industry. Resour Policy 63:101449. https://doi.org/10.1016/j.resourpol.2019.101449

26. Lin B, Wang X (2014) Promoting energy conservation in China's iron \& steel sector. Energy 73:465-474. https://doi.org/10.1016/j.energy.2014.06.036

27. Ma B, Yu Y (2017) Industrial structure, energy-saving regulations and energy intensity: Evidence from Chinese cities. J Clean Prod 141:15391547. https://doi.org/10.1016/j.jclepro.2016.09.221

28. Meng J, Mi Z, Yang H, Shan Y, Guan D, Liu J (2017) The consumption-based black carbon emissions of China's megacities. J Clean Prod 161:1275-1282. https://doi.org/10.1016/j.jclepro.2017.02.185

29. Mielnik O, Goldemberg J (2002) Foreign direct investment and decoupling between energy and gross domestic product in developing countries. Energy Policy 30:87-89. https://doi.org/10.1016/S0301-4215(01)00080-5

30. Moser P, Voena A (2012) Compulsory licensing: Evidence from the Trading with the Enemy Act. Am Econ Rev 102:396-427. https://doi.org/10.1257/aer.102.1.396

31. O'Meara S (2020) China's plan to cut coal and boost green growth. Nature 584:S1-S3. https://doi.org/10.1038/d41586-020-02464-5

32. Omri A, Nguyen DK, Rault C (2014) Causal interactions between CO2 emissions, FDI, and economic growth: Evidence from dynamic simultaneous-equation models. Econ Model 42:382-389. https://doi.org/10.1016/j.econmod.2014.07.026

33. Ren S, Yuan B, Ma X, Chen X (2014) International trade, FDI (foreign direct investment) and embodied CO2 emissions: A case study of chinas industrial sectors. China Econ Rev 28:123-134. https://doi.org/10.1016/j.chieco.2014.01.003

34. Shao S, Tian Z, Yang L (2017) High speed rail and urban service industry agglomeration: Evidence from China's Yangtze River Delta region. J Transp Geogr 64:174-183. https://doi.org/10.1016/j.jtrangeo.2017.08.019

35. Shi X, Rioux B, Galkin P (2018) Unintended consequences of China's coal capacity cut policy. Energy Policy 113:478-486. https://doi.org/10.1016/j.enpol.2017.11.034

36. Shou MH, Wang ZX, Li DD, Wang Y (2020) Assessment of the air pollution emission reduction effect of the coal substitution policy in China: an improved grey modelling approach. Environ Sci Pollut Res 27:34357-34368. https://doi.org/10.1007/s11356-020-09435-3

37. Stone CA, Sobel ME (1990) The robustness of estimates of total indirect effects in covariance structure models estimated by maximum. Psychometrika 55:337-352. https://doi.org/10.1007/BF02295291

Page $11 / 12$ 
38. Tan R, Lin B (2018) What factors lead to the decline of energy intensity in China's energy intensive industries? Energy Econ 71:213-221. https://doi.org/10.1016/j.eneco.2018.02.019

39. Taylor M, Copeland B (1997) A Simple Model of Trade, Capital Mobility, and the Environment. U.B.C. Dep. Econ

40. Tian X, Chang M, Shi F, Tanikawa H (2014) How does industrial structure change impact carbon dioxide emissions? A comparative analysis focusing on nine provincial regions in China. Environ Sci Policy 37:243-254. https://doi.org/10.1016/j.envsci.2013.10.001

41. Wang D, Han B (2017) Effects of indigenous R\&D and foreign spillover on energy intensity in China. J Renew Sustain Energy 9. https://doi.org/10.1063/1.4984624

42. Wang H, Dong C, Liu Y (2019) Beijing direct investment to its neighbors: A pollution haven or pollution halo effect? J Clean Prod $239: 118062$. https://doi.org/10.1016/j.jclepro.2019.118062

43. Wang H, Wang Y, Wang, Haikun, Liu M, Zhang Y, Zhang R, Yang J, Bi J (2014) Mitigating greenhouse gas emissions from China's cities: Case study of Suzhou. Energy Policy 68:482-489. https://doi.org/10.1016/j.enpol.2013.12.066

44. Wang K, Yin H, Chen Y (2019) The effect of environmental regulation on air quality: A study of new ambient air quality standards in China. J Clean Prod 215:268-279. https://doi.org/10.1016/j.jclepro.2019.01.061

45. Wu S, Ding S (2021) Efficiency improvement, structural change, and energy intensity reduction: Evidence from Chinese agricultural sector. Energy Econ 99:105313. https://doi.org/10.1016/j.eneco.2021.105313

46. Xi F, Geng Y, Chen X, Zhang Y, Wang X, Xue B, Dong H, Liu Z, Ren W, Fujita T, Zhu Q (2011) Contributing to local policy making on GHG emission reduction through inventorying and attribution: A case study of Shenyang, China. Energy Policy 39:5999-6010.

https://doi.org/10.1016/j.enpol.2011.06.063

47. Xia C, Wang Z, Xia Y (2021) The drivers of China's national and regional energy consumption structure under environmental regulation. J Clean Prod 285:124913. https://doi.org/10.1016/j.jclepro.2020.124913

48. Yang HY (2000) Coal consumption and economic growth in Taiwan. Energy Sources 22:109-115. https://doi.org/10.1080/00908310050014081

49. Yang X, Teng F (2018) The air quality co-benefit of coal control strategy in China. Resour Conserv Recycl 129:373-382. https://doi.org/10.1016/j.resconrec.2016.08.011

50. Yoo SH (2006) Causal relationship between coal consumption and economic growth in Korea. Appl Energy 83:1181-1189. https://doi.org/10.1016/j.apenergy.2006.01.010

51. Zhang JF, Deng W (2010) Industrial structure change and its eco-environmental influence since the establishment of municipality in Chongqing, China. Procedia Environ Sci 2:517-526. https://doi.org/10.1016/j.proenv.2010.10.056

52. Zhang L, Yang M, Zhang P, Hao Y, Lu Z, Shi Z (2021) De-coal process in urban China: What can we learn from Beijing's experience? Energy 230:120850. https://doi.org/10.1016/j.energy.2021.120850

53. Zhao X, Lynch JG, Chen Q (2010) Reconsidering Baron and Kenny: Myths and truths about mediation analysis. J Consum Res 37:197-206. https://doi.org/10.1086/651257

54. Zheng Y, Qi J, Chen X (2011) The effect of increasing exports on industrial energy intensity in China. Energy Policy 39:2688-2698. https://doi.org/10.1016/j.enpol.2011.02.038 